\title{
Early-onset vs. Late-onset Parkinson's disease: A Clinical-pathological Study
}

\author{
Leslie Wayne Ferguson, Ali H. Rajput, Alexander Rajput
}

\begin{abstract}
Background: Several studies have compared early-onset Parkinson disease (EOPD) and late-onset Parkinson disease (LOPD) but most are not based on autopsy confirmed cases. Methods: We compared clinical and pharmacological profiles, time to reach irreversible Hoehn and Yahr (H\&Y) Stage 3 and levodopa motor complications in autopsy confirmed EOPD and LOPD cases. Results: At first clinic visit EOPD cases were younger but had longer disease duration and they died at a younger age (all $\mathrm{p}<0.0001)$. Anti-Parkinsonian drug use, including levodopa, was significantly delayed in EOPD. Lifetime use of amantadine $(p<0.05)$ and dopamine agonists $(p<0.01)$ were higher in EOPD. While lifetime use of levodopa was similar in the two groups, levodopa was used for a significantly longer period by EOPD $(p<0.0001)$. EOPD had a higher cumulative incidence of dyskinesias $(p<0.01)$, wearing-off $(p<0.01)$, and on-off $(p<0.01)$. However, the time to dyskinesia onset was similar in the two groups. The threshold to wearing-off was much longer in EOPD (p $<0.01)$. $\mathrm{H} \& \mathrm{Y}$ stage profile at first visit was similar in the two groups. The duration from disease onset to reach irreversible $\mathrm{H} \& \mathrm{Y}$ stage 3 was significantly longer in EOPD. Conclusions: Our observations indicate that progression of PD is slower in EOPD and suggest that the preclinical interval in this group is longer. These findings can be used for case selection for drug trials and studies of the pathogenesis of PD.
\end{abstract}

RÉSUMÉ: Maladie de Parkinson à début précoce et à début tardif : étude anatomo-clinique. Contexte: Plusieurs études ont comparé la maladie de Parkinson à début précoce (MPDP) et la maladie de Parkinson à début tardif (MPDT), mais la plupart de ces études ne reposent pas sur des cas dont le diagnostic a été confirmé en anatomopathologie. Méthode : Nous avons comparé les profiles cliniques et pharmacologiques, le délai pour atteindre le stade 3 irréversible à l'échelle de Hoehn and Yahr (H\&Y) et les complications motrices du traitement par la lévodopa chez des cas de MPDP et de MPDT confirmés à l'autopsie. Résultats : Au moment de la première consultation, les cas de MPDP étaient plus jeunes, mais leur maladie durait depuis plus longtemps et ils sont morts plus jeunes $(\mathrm{p}<0,0001)$. L'utilisation de médicaments antiparkinsoniens, incluant la lévodopa, était significativement plus tardive chez les cas de MPDP. L'utilisation de l'amantadine au cours de la vie $(\mathrm{p}<0,05)$ et d'agonistes de la dopamine $(\mathrm{p}<0,01)$ étaient plus élevée chez les patients atteints de MPDP. Bien que la prise de lévodopa était similaire dans les deux groupes, la lévodopa avait été utilisée pendant plus longtemps par les patients atteints de MPDP ( $\mathrm{p}<0,0001)$. L'incidence cumulative de dyskinésies était plus élevée chez les cas de MPDP ( $<<0,01)$, ainsi que les signes de l'épuisement de l'effet thérapeutique en fin de dose $(\mathrm{p}<0,01)$ et les fluctuations de la motricité, phénomène « on-off », $(\mathrm{p}<0,01)$. Cependant, le temps écoulé avant le début des dyskinésies était similaire dans les deux groupes. Le seuil de l'épuisement de l'effet thérapeutique était beaucoup plus long chez les patients atteints de la MPDP ( $\mathrm{p}<0,01)$. Le profile du stade de H\&Y à la première consultation était similaire dans les deux groupes. Le temps écoulé depuis le début de la maladie jusqu' au stade 3 irréversible de H\&Y était significativement plus long chez les patients atteints de MPDP. Conclusions : Nos observations indiquent que la progression de la MP est plus lente chez les patients atteints de la MPDP ce qui suggère que l'intervalle préclinique est plus long chez ce groupe de patients. Ces observations peuvent être utilisées pour sélectionner les patients à inclure dans les essais thérapeutiques et les études sur la pathogenèse de la MP.

Keywords: Age of Onset, Early-onset, Late-Onset, Parkinson disease

doi:10.1017/cjn.2015.244

Can J Neurol Sci. 2016; 43: 113-119

Age is the most important risk factor for Parkinson's disease (PD). Mean onset age reported by most studies is in the early $60 \mathrm{~s}^{1-3}$ Early onset of PD (EOPD) lacks a consistent definition. Some studies defined EOPD as onset of motor symptoms before age $40^{4-8}$ but others expanded the definition to include onset before age 50, ${ }^{5,9-12}$ Most studies found that between five to ten percent of all PD cases

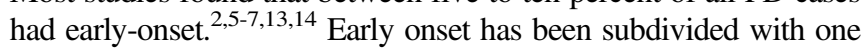
group having onset less than 21 years of age, termed juvenile. This is a very rare, often familial form with somewhat atypical clinical presentation and pathology that may not be Lewy body disease. ${ }^{5}$ The reported age for late-onset PD (LOPD) is also not uniform ${ }^{6,8,10-12}$ but generally includes those with onset after age 60 years. Very few EOPD studies have used pathologically confirmed cases of PD. ${ }^{10,15}$
Early onset PD cases are reported to have a more benign progression of disease, delayed onset of falls and longer survival. ${ }^{5,12,15-16}$ The EOPD cases are less likely to have gait disturbance as the presenting symptom and have more pronounced rigidity and bradykinesia compared to LOPD. ${ }^{8,10}$

From the Division of Neurology, University of Saskatchewan, Saskatoon, Saskatchewan, Canada.

Received August 5, 2014. Final Revisions Submitted April 21, 2015. Correspondence to: Alexander Rajput, Division of Neurology, University of Saskatchewan, Room 1663, Royal University Hospital, 103 Hospital Drive, Saskatoon, Saskatchewan, Canada S7N 0W8. E-mail: alex.rajput@usask.ca 
Most PD cases benefit from levodopa ${ }^{17}$ but, with prolonged use, the benefit declines as patients develop motor complications including dyskinesias, end-of-dose wearing-off (W-Off), and onoff phenomenon (On-Off). ${ }^{18,19}$ A clinicopathological study reported that those with higher cumulative incidence of levodopa induced motor complications were younger age at initiation of treatment, were on a larger daily dose of levodopa, and were on the drug for longer period of time. This group also had longer follow-up and longer survival. ${ }^{19}$ These cases were not dichotomized by age of onset. Another clinicopathological study reported on the severity of motor complications. ${ }^{18}$ Those with moderate to severe motor complications were younger at onset and had longer disease duration compared to patients with mild motor complications. ${ }^{18}$ Some studies report that EOPD cases received a higher daily dose of levodopa ${ }^{12,15}$ but others did not find such difference. ${ }^{20}$ Early onset PD cases are more likely to have ever been treated with anticholinergics and dopamine agonists compared to LOPD. ${ }^{8}$

Two recent reviews reported that EOPD had less frequent gait disorders and slower disease progression but more frequent and earlier onset of levodopa induced dyskinesias and other motor complications. ${ }^{5,13}$ The majority of EOPD studies lack pathological confirmation of diagnosis and may thus have included other Parkinsonian variants. ${ }^{21,22}$ We present a study of autopsy confirmed PD cases. The objective was to compare clinical characteristics, pharmacological profile including complications of levodopa treatment, and progression of disease in EOPD and LOPD cases.

\section{Methods}

\section{Patients and Data}

All patients were assessed at the Movement Disorders Clinic Saskatchewan (MDCS) by one or both movement disorders neurologists (AHR, AR) between 1968 and 2009. All residents of Saskatchewan carry a general tax-funded health care and prescription drug insurance. Patients are generally referred by family physicians and as a rule are evaluated at 6 to 12 month intervals. Pertinent information on patient demographics, motor symptoms, medication use and side effects, and motor complications were obtained. Hoehn and Yahr (H\&Y) stage was recorded at each clinic visit ${ }^{23}$ but, for practical considerations, patients were not always evaluated in ON or OFF phase, as has been noted by others. ${ }^{24}$ For this study all variants of dyskinesias (peak dose, biphasic, square-wave, and off-period dystonia) were classified collectively. ${ }^{19}$ A predictable decline in motor function at the end of levodopa dose when the patient had a previously stable response and was receiving three or more daily doses, which improved with next dose was classified as W-Off. ${ }^{19}$ Sudden, unpredictable, and pronounced short-duration worsening of Parkinsonian features, which resolved spontaneously, was classified as On-Off. ${ }^{19}$ These motor complications (dyskinesias, W-Off, On-Off), symptomatic benefits, and freezing of gait (FOG) were all reported as cumulative incidence. Early onset of dyskinesias on large doses of levodopa during the 1960s led the MDCS to use lower doses. ${ }^{25}$ Plain levodopa dose was converted to levodopa-carbidopa combination using 5:1 equivalency. ${ }^{26} \mathrm{We}$ report these doses as levodopa-carbidopa combination.

Prior to 1987 , upper limb bradykinesia, rigidity and tremor were measured according to Webster ${ }^{27}$ and global severity by H\&Y scale. ${ }^{23}$ Subsequently, modified Unified Parkinson Disease Rating Scale (UPDRS) and modified H\&Y scale have been used. ${ }^{28}$ In order to maintain uniformity the modified H\&Y stage 1.5 was reclassified as stage 1 and stage 2.5 as stage $3 .^{29}$ Hoehn and Yahr scale has a high Spearman's correlation with UPDRS and other rating scales that measure motor impairment. ${ }^{30}$ We also conducted a KaplanMeier survival analysis of irreversible progression to $\mathrm{H} \& \mathrm{Y}$ stage 3 from disease onset. For this analysis we included patients who were documented to be at a H\&Y lower than stage 3 at first MDCS visit and then at any future MDCS visit progressed irreversibly to H\&Y stage 3. Progression was considered irreversible if the patient remained at $\mathrm{H} \& \mathrm{Y}$ stage 3 and did not reverse on optimal treatment. ${ }^{31}$ Between clinic visits any patient concerns, unusual events, or medication adjustments were recorded prospectively and subsequently confirmed at the next clinic visit. Any anti-Parkinsonian drug changes required between MDCS visits were recorded prospectively. Patients were also instructed to contact the MDCS neurologists for any concerns between visits. All clinical data collected on an ongoing basis were preserved in our laboratory.

Clinical diagnosis of parkinsonism (PS) was based on the presence of at least two of three cardinal motor symptoms of resting tremor, rigidity, and bradykinesia. ${ }^{22}$ Final diagnosis of PD was based on pathological findings. ${ }^{21,22,32-34}$ Disease onset was defined by recognition of the presence of any one of tremor, bradykinesia or gait disturbance as reported by the patient or other observer. For this study we focused on only PD cases. Inclusion criteria for EOPD were: patients with clinical symptoms of PS, autopsy confirmed pathological diagnosis of Lewy body PD, and documented onset of motor symptoms between 21 and 50 years old. Brain material was available on 13 of 22 cases for genetic testing; no mutations were identified in LRRK2 (G2019S), SNCA, PARK2 (parkin), or DJ-1 (unpublished data). A novel genetic mutation (DNAJC13) was identified in one familial group but none of these cases were included in this study. ${ }^{35}$ A comparison group of LOPD was identified from MDCS cases by a random number generator with inclusion criteria of: clinical motor symptoms of PS starting at 65 years of age or older and autopsy confirmation of PD.

\section{Autopsy and Brain Study}

All patients are offered autopsy at no cost and are assured that their decision would not impact ongoing care at MDCS. Consent for autopsy was granted by the next-of-kin after death of the patient. The University of Saskatchewan Ethics Board granted approval for the use of the brain for research. Retrieval, preservation and histological preparation of brain tissue has been described elsewhere. ${ }^{19}$ Pathologic studies were performed by qualified neuropathologists. Only those patients with marked substantia nigra neuronal loss and Lewy body inclusions without evidence of other Parkinsonian-related pathology were included. ${ }^{31}$ Other PS variants such as multiple system atrophy and progressive supranuclear palsy were excluded. ${ }^{19,22,34,36}$ Cases that had ablative surgery for PD were also excluded.

\section{Statistical Analysis}

Continuous variables were described by mean, standard deviation, median, and ranges. Categorical variables were described by frequency and percent. Differences between EOPD and LOPD subjects for characteristics of interest were tested by 
Table 1: Patient characteristics of Early-Onset and Late-Onset Parkinson's disease at initial MDCS assessment

\begin{tabular}{|c|c|c|}
\hline & $\begin{array}{c}\text { Early-Onset } \\
\quad(n=22)\end{array}$ & $\begin{array}{l}\text { Late-Onset } \\
\quad(n=44)\end{array}$ \\
\hline Male Sex, $\mathrm{n}(\%)$ & $16(72.7)$ & $30(68.2)$ \\
\hline Family History MD, $n(\%)$ & $6(27.3)$ & $16(36.4)$ \\
\hline \multicolumn{3}{|l|}{ H\&Y Stage at first assessment, $n(\%)$} \\
\hline 1 & 0 & $9(20.5)$ \\
\hline 2 & $11(50.0)$ & $18(40.9)$ \\
\hline 3 & $9(40.9)$ & $14(31.8)$ \\
\hline 4 & $1(4.5)$ & $2(4.5)$ \\
\hline 5 & $1(4.5)$ & $1(2.3)$ \\
\hline Median (range) & $2.5(2.0-5.0)$ & $2.0(1.0-5.0)$ \\
\hline \multicolumn{3}{|l|}{ Motor Symptom at onset, $n(\%)$} \\
\hline Tremor, only & $10(45.5)$ & $26(59.1)$ \\
\hline Bradykinesia and Tremor & $5(22.7)$ & $4(9.1)$ \\
\hline Bradykinesia, only & $7(31.8)$ & $11(25.0)$ \\
\hline Postural Instability Gait Difficulty & $0(0)$ & $3(6.8)$ \\
\hline \multicolumn{3}{|l|}{ Age at Symptom Onset, $y r s$} \\
\hline Mean (SD) & $44.5(5.4)$ & $72.0(5.4) *$ \\
\hline Range & $29-50$ & $65-85$ \\
\hline \multicolumn{3}{|l|}{ Age at first assessment, $y r s$} \\
\hline Mean (SD) & $57.3(8.1)$ & $74.9(5.7) *$ \\
\hline Range & $44-72$ & $66-88$ \\
\hline \multicolumn{3}{|l|}{$\begin{array}{l}\text { Disease Duration at first assessment, } \\
y r s\end{array}$} \\
\hline Mean (SD) & $12.8(10.2)$ & $2.9(2.9) *$ \\
\hline Range & $2-43$ & $0-16$ \\
\hline \multicolumn{3}{|l|}{ Survival from Onset, yrs } \\
\hline Mean (SD) & $26.6(9.5)$ & $10.2(3.7) *$ \\
\hline Range & $8-47$ & $4-21$ \\
\hline \multicolumn{3}{|l|}{ Age at Death, $y r s$} \\
\hline Mean (SD) & $70.6(9.9)$ & $81.7(5.5) *$ \\
\hline Range & $48-84$ & $70-94$ \\
\hline \multicolumn{3}{|l|}{ Years of follow-up, yrs } \\
\hline Mean (SD) & $11.5(6.7)$ & $5.1(3.1) *$ \\
\hline Range & $3-23$ & $1-12$ \\
\hline
\end{tabular}

*p < 0.0001. MD - Movement disorders; MDCS - Movement Disorders Clinic Saskatchewan; H\&Y - Hoehn and Yahr; SD - standard deviation; yrs - years.

using Chi-squared or Fisher exact tests and t-tests or Wilcoxon rank sum test where appropriate. Kaplan-Meier survival curves were generated for time from symptom onset to irreversible H\&Y stage 3 for both EOPD and LOPD groups. All statistical analysis was performed in SAS ver. 9.1 software.

\section{RESUlts}

During the study period (1968-2009) 239 cases had pathologically confirmed diagnosis of PD of which 24 were classified as
Table 2: Pharmacological characteristics of Early-Onset and Late-Onset Parkinson's disease

\begin{tabular}{|c|c|c|}
\hline & $\begin{array}{c}\text { Early-Onset } \\
\quad(n=22)\end{array}$ & $\begin{array}{l}\text { Late-Onset } \\
\quad(n=44)\end{array}$ \\
\hline \multicolumn{3}{|l|}{ First Anti-Parkinsonian Medication, $n(\%)^{1}$} \\
\hline Levodopa & $13(59.1)$ & $23(52.3)$ \\
\hline Dopamine agonist & 0 & $2(4.5)$ \\
\hline MAO-B inhibitor & 0 & $6(13.6)$ \\
\hline Anti-cholinergic & $8(36.4)$ & $4(9.1)$ \\
\hline Amantadine & $1(4.5)$ & $9(20.5)$ \\
\hline $\begin{array}{l}\text { Patients Taking Levodopa at first visit, } \\
n(\%)\end{array}$ & $16(72.7)$ & $14(31.8) * *$ \\
\hline \multicolumn{3}{|l|}{ Disease Duration at } \\
\hline $\begin{array}{l}\text { First Anti-Parkinsonian medication, mean } \\
y r s(S D)\end{array}$ & $7.0(7.2)$ & $2.3(2.0) * *$ \\
\hline Levodopa Initiation, mean yrs $(S D)$ & $8.3(7.5)$ & $3.0(2.1) * *$ \\
\hline \multicolumn{3}{|l|}{$\begin{array}{l}\text { Anti-Parkinsonian Medication Ever Used, } \\
n(\%)^{2}\end{array}$} \\
\hline Levodopa & $22(100)$ & $42(95.5)$ \\
\hline Amantadine & $18(81.8)$ & $24(54.5) *$ \\
\hline Dopamine agonist & $17(77.3)$ & $15(34.1) * *$ \\
\hline MAO-B inhibitor & $8(38.1)$ & $14(31.8)$ \\
\hline Anticholinergic & $14(63.6)$ & $7(15.9) * * *$ \\
\hline COMT inhibitor & $2(9.1)$ & $3(6.8)$ \\
\hline $\begin{array}{l}\text { Documented improvement on Levodopa, } \\
n(\%)\end{array}$ & $18(81.8)$ & $38(86.4)$ \\
\hline $\begin{array}{l}\text { Adverse effects of Levodopa therapy, } \\
n(\%)^{3}\end{array}$ & $6(27.3)$ & $9(21.4)$ \\
\hline \multicolumn{3}{|c|}{$\begin{array}{l}{ }^{2} \text { Alone or in combination with other anti-Parkinsonian Medication } \\
\text { (either at the MDCS or other facility) } \\
{ }^{3} \text { Adverse effects included nausea, GI upset, syncope, headache, } \\
\text { sleepiness }\end{array}$} \\
\hline
\end{tabular}

EOPD. Two EOPD cases were excluded due to lack of longitudinal follow-up. The EOPD group for this study consisted of 22 pathologically confirmed cases. Forty-four LOPD cases were randomly selected from the MDCS data file for comparison.

Table 1 summarizes baseline characteristics. There was no statistical difference between EOPD and LOPD regarding sex, median H\&Y score, or family history of movement disorders. The distribution of H\&Y stages at first MDCS visit was similar between the two groups. Early onset PD had much longer duration of symptoms at first MDCS visit, had longer follow-up and longer survival, but died at a much younger age compared to LOPD. Although not statistically significant, the presenting symptom of bradykinesia or both tremor and bradykinesia were slightly more common in EOPD but tremor onset was more common in the LOPD. Only three cases had postural instability and gait difficulty (PIGD) onset and all were LOPD. Since only six (27.3\%) EOPD cases had an age of onset less than 40 years, we did not conduct a separate comparison of that group with the LOPD. 
Table 3: Motor Complications of Levodopa Therapy in Early-Onset and Late-Onset Parkinson's Disease

\begin{tabular}{|c|c|c|}
\hline & Early-Onset $(n=22)$ & Late-Onset $(n=44)$ \\
\hline \multicolumn{3}{|l|}{ Cumulative incidence of MC, $n(\%)^{1}$} \\
\hline Any one or more & $18(81.8)$ & $24(55.8) *$ \\
\hline All three & $6(28.6)$ & $0 * *$ \\
\hline Dyskinesia, with or without other MC & $18(81.8)$ & $20(46.5) * *$ \\
\hline W-Off, with or without other MC & $14(66.7)$ & $12(27.9) * *$ \\
\hline On-Off, with or without other MC & $7(31.8)$ & $0 * *$ \\
\hline \multicolumn{3}{|l|}{ Freezing of gait } \\
\hline Cumulative incidence, $n(\%)$ & $9(40.9)$ & $12(27.3)$ \\
\hline Years from onset, mean $(S D)$ & $17.7(7.2)$ & $7.3(3.9) * *$ \\
\hline Years from Levodopa initiation, mean(SD) & $8.3(7.5)$ & $3.0(2.1) * *$ \\
\hline \multicolumn{3}{|l|}{ Years from Levodopa initiation to onset of: } \\
\hline Dyskinesia & $3.3(4.7)$ & $3.8(2.6)$ \\
\hline W-Off & $8.8(5.6)$ & $3.3(2.4) * *$ \\
\hline On-Off & $8.3(4.2)$ & 0 \\
\hline \multicolumn{3}{|c|}{ Levodopa $^{2}$ dose at the time of the onset of, $\mathrm{mg} /$ day: } \\
\hline Dyskinesia & $619.4(273.9)$ & $500.0(183.5)$ \\
\hline W-Off & $614.3(206.1)$ & $437.5(179.8) *$ \\
\hline On-Off & $692.9(242.3)$ & 0 \\
\hline
\end{tabular}

$* \mathrm{p}<0.05 * * \mathrm{p}<0.01 * * * \mathrm{p}<0.0001$

$\mathrm{SD}$ - standard deviation

MC-Motor Complications

W-Off - wearing off

On-Off - On-Off Phenomenon

${ }^{1}$ Motor Complications are Wearing off, On-off phenomenon and dyskinesias

${ }^{2}$ This dose represents levodopa/carbidopa conversion as indicated in the Methods section

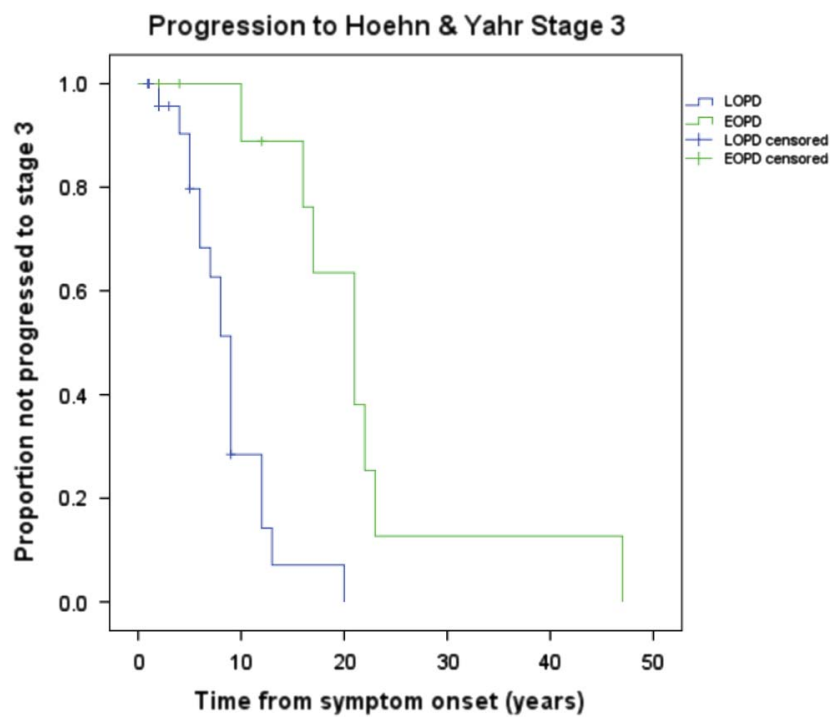

Figure 1: Kaplan Meier curves for EOPD versus LOPD comparing time to irreversible $H \& Y$ Stage 3 from disease onset. Mean time to $H \& Y$ stage 3 was 22.3 years (95\% CI: $14.8-29.8)$ for EOPD and 8.9 years (95\% CI: 6.9-10.9) for $L O P D$.
The pharmacological profile is summarized in Table 2. Levodopa was the most common initial anti-Parkinsonian medication prescribed by a physician regardless of onset age. There was no statistical difference between the two groups regarding which anti-Parkinsonian medication was used first. Referring physicians were more likely to have prescribed an anticholinergic as the initial anti-Parkinsonian medication. A much greater proportion of EOPD had been prescribed levodopa prior to first MDCS visit $(p<0.01)$. Lifetime medication use demonstrated that a significantly greater proportion of EOPD cases were prescribed a dopamine agonist $(\mathrm{p}<0.01)$, amantadine $(\mathrm{p}<0.05)$, and anti-cholinergic $(\mathrm{p}<0.0001)$ medications. Early onset PD had longer disease duration prior to levodopa treatment. Additionally, EOPD were on levodopa therapy for an average of 17.3 years compared to only 7.5 years in LOPD $(\mathrm{p}<0.0001)$.

During the study interval a greater proportion of EOPD developed one or more motor complications (Table 3). All 18 EOPD with motor complications had dyskinesia. Of the 24 LOPD with motor complications, all but four cases had dyskinesia; those four had only W-Off (data not shown). On-off phenomeanon was the least common motor complication. While there was no statistically significant difference in the cumulative incidence of FOG, the EOPD cases experienced FOG much later in the course of disease as well as after levodopa initiation $(\mathrm{p}<0.01)$. In EOPD, W-Off developed after longer duration of LD use $(p<0.01)$ and were on a 
higher daily dose of LD $(\mathrm{p}<0.05)$. There was no statistically significant difference between EOPD and LOPD for the development of dyskinesias.

Irreversible progression of disease, in spite of optimal drug therapy, is summarized in Figure 1. Early onset PD had a significantly longer duration of symptoms before reaching irreversible $\mathrm{H} \& \mathrm{Y}$ stage 3 from symptom onset compared to LOPD. The mean time from symptom onset to irreversible H\&Y stage 3 was 22.3 years (95\%CI: 14.8-29.8) for EOPD and 8.9 years $(95 \%$ CI: 6.9-10.9) for LOPD. Four (18.2\%) EOPD and 14 (31.8\%) LOPD did not progress during follow-up at MDCS or, in other words, they had the same or lower H\&Y score at their final MDCS visit compared to the first visit. This difference did not reach statistical significance $(p=0.38)$. For EOPD cases there was no significant difference between the cases who did not progress and the remainder of that group concerning survival $(p=0.15)$, mean number of years of MDCS follow-up $(p=0.30)$, or mean years from final visit to death $(p=0.54)$. For LOPD there was no significant difference between cases who did not progress and the remainder of the LOPD group concerning survival $(\mathrm{p}=0.22)$ and mean years from final visit to death $(\mathrm{p}=0.81)$. However, the mean years of follow-up at the MDCS was significantly shorter $(\mathrm{p}=0.007)$ for those cases who did not progress (mean $(\mathrm{SD})=$ 3.3 (2.5)) compared to the remainder of the LOPD group $(\operatorname{mean}(\mathrm{SD})=5.9(3.1))$.

\section{Discussion}

Early-onset of PD has been defined as onset between 21 and $40,{ }^{4-8}$ or up to age $50 .^{5,9-12}$ We used onset age 21 to 50 years in EOPD. There were no genetic mutations present in any EOPD or LOPD cases and all cases had Lewy body pathology. The prevailing belief is that there is a higher frequency of family history in early-onset PD. However, as pointed out by several authors, some of these studies included childhood and juvenile onset which would thus include a higher proportion of genetic variants such as PARK2 (i.e. parkin). ${ }^{7,37}$ When juvenile and early-onset cases are appropriately separated the difference in frequency of family history is large. In one study, $16 \%$ of young onset cases had at least one affected first- or second-degree family member while $50 \%$ of juvenile-onset cases reported at least one first-degree family member with PS. $^{38}$ Similar to our study, others have demonstrated that when genetic variants were accounted for, the difference between EOPD and LOPD for frequency of family history is not statistically significant. ${ }^{10,39,40}$

The autopsy confirmed cases reflect the overall MDCS population in terms of the frequency of EOPD. Additionally, EOPD and LOPD groups in this study do not differ from those age groupings in our overall clinic population concerning gender, age of disease onset, age at first visit, and survival. However, EOPD cases had more severe global disability at first visit. Fifty percent of the EOPD cases had H\&Y score of 3 or greater compared to $15 \%$ in the rest of our clinic population (Unpublished data). This could introduce a bias as younger onset of disease with more severe disability may lend well to brain donation, though the option of autopsy is offered to all patients at some point. There is very limited literature on comparison of EOPD and LOPD in autopsy confirmed cases. One study used pathologically confirmed cases but, unlike our report, the clinical and pathological investigations were not conducted on the same group of cases. ${ }^{10}$ Another study used pathologically confirmed PD cases but the primary focus of the study was to characterize PD subtypes and cases were not dichotomized to compare EOPD and LOPD. ${ }^{15}$

There was no statistical difference for the mode of motor onset between EOPD and LOPD in our cases. Previous comparative clinical studies show no consistent difference for tremor onset between EOPD and LOPD ${ }^{6,8,10-13}$ but EOPD cases were less likely to present as gait disturbance. The higher incidence of gait disturbance at onset in LOPD cases may represent confounding effect of old age and co-morbidity. ${ }^{13}$ Alternatively, it may reflect rapid disease progression in LOPD. ${ }^{41}$ Similar to other observations, EOPD cases attended our clinic after longer disease duration. ${ }^{8,10,12}$ Despite that, EOPD cases came to our clinic at similar global disability (H\&Y score) as LOPD cases. Other studies that evaluated baseline $\mathrm{H} \& \mathrm{Y}$ score also found no significant difference between early-onset and late-onset PD. ${ }^{6,8,39,42,43}$ However, none of the pathologically confirmed studies evaluated $\mathrm{H} \& \mathrm{Y}$ score at baseline. ${ }^{10,15}$

Taken together, these observations indicate that PD patients come to Movement Disorders clinics after reaching a specific level of disability rather than after a certain duration of symptoms. This suggests that EOPD cases are initially less bothered by slowly progressing symptoms. Similar to previous reports, we found that EOPD died at a much younger age ${ }^{10,15}$ but also had much longer duration of symptoms, which is consistent with slower disease progression in EOPD. An alternative explanation is that LOPD experience a more rapid disease progression as onset occurs during a time of life when there are more co-morbidities and there is lower substantia nigra $(\mathrm{SN})$ age related reserve. There are normal age related cellular processes predisposing to neurodegeneration along with a concomitant loss of compensatory strategies against cell damage and death. ${ }^{44}$ The pathogenesis in PD also has a cascade of age-related events that lead to cell death. Cell loss in the SN pars compacta in PD occurs preferentially in the ventral portion while in normal aging the cell loss occurs preferentially in the dorsal portion at a greater than 3:1 ratio. ${ }^{45}$ As such, the older chronological age of LOPD could add enough normal cell loss, in addition to that occurring in PD pathology, to account for the more rapid progression of disease compared to EOPD.

Levodopa was the most common initial drug prescribed in both groups. Prescription of anti-Parkinsonian drugs including levodopa was significantly delayed after onset in EOPD compared to LOPD. As reported in other studies ${ }^{8,39}$ our EOPD cases received anticholinergics and dopamine agonists more often. It is common practice at MDCS to use amantadine in patients with mild symptoms and as an adjuvant therapy to help control troublesome dyskinesias. ${ }^{46,47}$ This may account for the higher amantadine use in our EOPD group. A handful of EOPD publications reported that the average time from symptom onset to first use of antiParkinsonian medications ranged from 2.1 to 3.3 years ${ }^{12,15,48}$, two of them reporting only on time to levodopa use. In our study the mean time to start any anti-Parkinsonian medication was much longer. We speculate that some EOPD patients may have delayed seeking care for mild disability given they were mostly younger males. Additionally, the diagnosis of PD may have been missed or not even considered by the referring physician because of the young age of these patients.

The higher rate of motor complications observed in our EOPD cases is consistent with similar observations in other comparative studies, ${ }^{8,10-12,20}$ in cluster analyses, ${ }^{15,39,49}$ and in studies that investigated factors linked to levodopa complications. ${ }^{19,50-52}$ 
There is no consensus on how soon after commencing levodopa therapy the dyskinesias manifest. Some found no significant difference between EOPD and LOPD ${ }^{10,12}$ as in our study, while others reported that dyskinesias occurred sooner after levodopa initiation in the early-onset group. ${ }^{8}$ No significant difference in levodopa dose at dyskinesia onset has been reported between EOPD and LOPD. ${ }^{10,12,20}$ Although daily levodopa dose was marginally higher at dyskinesia onset in our EOPD cases, the difference was not significant. Both groups manifest dyskinesias after comparable duration and comparable levodopa dose at dyskinesia onset. Levodopa dose and duration of drug use and advanced disease are risk factors for dyskinesias. Our EOPD cases had longer duration of levodopa use and longer clinical follow-up (Table 1) which could account for the higher cumulative incidence of all motor complications (Table 3 ).

In contrast to previous reports we found that development of W-Off occurred much later after initiation of levodopa therapy in EOPD compared to LOPD. ${ }^{20,53}$ There is no agreement on the severity of functional decline required to classify W-Off. ${ }^{19}$ Additionally, mild W-Off is subjective and with greater awareness a mild decline can be easily identified. The W-Off in the two groups was measured by the same criteria by the same two neurologists. With progression of disease and longer duration of treatment the response to levodopa dose shortens and the therapeutic window narrows. ${ }^{50}$ As such, motor complications manifest and worsen with time. The higher frequency of dyskinesias and motor response fluctuations in EOPD could merely reflect the longer survival/follow-up in this group.

The H\&Y scale is frequently used as the marker of PD progression. ${ }^{41,53-57}$ In the study by Sato et al., ${ }^{53}$ young age of onset ( $<=50$ years) were slow to reach H\&Y stages III, IV, and $\mathrm{V}$ after onset. We found similar results concerning progression to $\mathrm{H} \& \mathrm{Y}$ stage 3. Although disease progression is slower in EOPD there is a more profound effect on life expectancy. One study showed that, when compared to the general population, youngonset PD (24-39 years) lost 11 years of life in absolute terms versus four years in late-onset PD (>65 years). ${ }^{13} \mathrm{We}$ also observed that time to levodopa initiation was much longer in EOPD. These results suggest that EOPD has a slower disease progression and the need for drug therapy is delayed. The longer time to $\mathrm{H} \& \mathrm{Y}$ stage advancement could indicate a blend of both unique characteristics of EOPD and the pharmacology of levodopa in this group. Given the pathological similarities between EOPD and LOPD in our cases, only the age-related difference is the most likely basis for the observed clinical differences.

The main weakness of this study is the relatively small sample size. Since EOPD account for about 5-10\% of PD cases, larger sample size of autopsy confirmed cases was not available. Another deficiency shared by all such studies is the use of the previously collected clinical data. Because there was no a priori hypothesis of differences between EOPD and LOPD, our approach avoids data collection bias. The data were collected by the same two neurologists for all cases in both of the groups over the same period. While our sample size of EOPD is small, all subjects were followed at the same clinic and had pathologically confirmed PD.

In conclusion, the impact of EOPD is profound. Although EOPD have longer disease progression and survival in absolute terms, it comes at the cost of increased years of life lost compared to both LOPD and the general population. Also, despite delayed initiation of levodopa, EOPD patients develop more complications of this therapy and are more likely to be treated with amantadine, dopamine agonists and anticholinergics. Pathology may be a key factor to the more rapid progression in LOPD due to the additive effect of age-related nigral cell loss. If a preclinical marker of PD were available, these cases could be used to study neuroprotective agents. These data can be used for case selection for symptomatic drug trials where therapeutic benefits, adverse effects and progression of disability are investigated.

\section{ACKNOWLEDGEMENTS}

The authors thank Michele Rajput for her valued input and the Regina Curling Classic, Greystone Golf Classic and The Royal University Hospital Foundation for unrestricted research grants.

\section{Disclosures}

Leslie Wayne Ferguson has nothing to disclose. Ali Rajput has the following disclosures: Parkinson Society Canada, Guest speaker, Honoraria. Alexander Rajput has the following disclosures: Greystone Golf Classic, Reseacher, Research support; Regina Curling Classic, Reseacher, Research support; Royal University Hospital Foundation, Reseacher, Research support.

\section{Statement of Authorship}

Leslie W. Ferguson: data collection, statistical analysis, manuscript: wrote first draft.

Ali Rajput: conception, data collection, manuscript: review and critique.

Alexander Rajput: data collection, manuscript: review and critique.

\section{REFERENCES}

1. Rajput AH. Early onset parkinsonism. Adv Clin Neurosci. 1996;6:27-35.

2. Rajput AH. Frequency and cause of Parkinson's disease. Can J Neurol Sci. 1992;19:103-7.

3. de Lau LM, Breteler MM. Epidemiology of Parkinson's disease. Lancet Neurol. 2006;5:525-35.

4. Quinn N, Critchley P, Marsden C. Young onset Parkinson's disease. Mov Disord. 1987;2:73-91.

5. Schrag A, Schott JM. Epidemiological, clinical, and genetic characteristics of early-onset parkinsonism. Lancet Neurol. 2006;5:355-63.

6. Giovannini P, Piccolo I, Genitrini S, et al. Early-onset Parkinson's disease. Mov Disord. 1991;6:36-42.

7. Gershanik OS. Early onset parkinsonism. Front Biosci. 2003;8: s568-78.

8. Gomez Arevalo G, Jorge R, Garcia S, Scipioni O, Gershanik O. Clinical and pharmacological differences in early- versus late-onset Parkinson's disease. Mov Disord. 1997;12:277-84.

9. Golbe L. Young-onset Parkinson's disease: a clinical review. Neurology. 1991;41:168-73.

10. Gibb WRG, Lees AJ. A comparison of clinical and pathological features of young- and old-onset Parkinson's disease. Neurology. 1988;38:1402-6.

11. Bostantjopoulou S, Logothetis J, Katsarou Z, Mentenopoulos G. Clinical observations in early and late onset Parkinson's disease. Funct Neurol. 1991;6:145-9.

12. Friedman A. Old-onset Parkinson's disease compared with youngonset disease: clinical differences and similarities. Acta Neurol Scand. 1994;89:258-61.

13. Wickremaratchi MM, Ben-Shlomo Y, Morris HR. The effect of onset age on the clinical features of Parkinson's disease. Eur J Neurol. 2009; $16: 450-6$. 
14. Schrag A, Ben-Shlomo Y, Quinn N. Cross sectional prevalence survey of idiopathic Parkinson's disease and parkinsonism in London. BMJ. 2000;321:21-2.

15. Selikhova M, Williams DR, Kempster PA, Holton JL, Revesz T, Lees AJ. A Clinico-pathological study of subtypes in Parkinson's disease. Brain. 2009;132:2947-57.

16. Pantelatos A, Fornadi F. Clinical features and medical treatment of Parkinson's disease in patient groups selected in accordance with age at onset. Adv Neurol. 1993;60:690-7.

17. Rajput AH, Rozdilsky B, Rajput A, Ang L. Levodopa efficacy and pathological basis of Parkinson syndrome. Clin Neuropharmacol. 1990;13(6):553-8.

18. Kempster PA, Williams DR, Selikhova M, Holton J, Revesz T, Lees AJ. Patterns of levodopa response in Parkinson's disease: A clinico-pathological study. Brain. 2007;130:2123-8.

19. Rajput AH, Fenton ME, Birdi S, et al. Clinical-pathological study of levodopa complications. Mov Disord. 2002;17:289-96.

20. Kostic V, Przedborski S, Flaster E, Sternic N. Early development of levodopa-induced dyskinesias and response fluctuations in young-onset Parkinson's disease. Neurology. 1991;41:202-5.

21. Hughes AJ, Daniel SE, Kilford L, Lees AJ. Accuracy of clinical diagnosis of idiopathic Parkinson's disease: A clinico-pathological study of 100 cases. J Neurol Neurosurg Psychiatry. 1992;55:181-4.

22. Rajput AH, Rozdilsky B, Rajput A. Accuracy of clinical diagnosis in Parkinsonism - A prospective study. Can J Neurol Sci. 1991; 18:275-8.

23. Hoehn MM, Yahr MD. Parkinsonism: onset, progression and mortality. Neurology. 1967;17:427-42.

24. Jankovic J, Kapadia AS. Functional decline in Parkinson disease. Arch Neurol. 2001;58:1611-5.

25. Rajput AH, Stern W, Laverty WH. Chronic low-dose levodopa therapy in Parkinson's disease: an argument for delaying levodopa therapy. Neurology. 1984;34:991-6.

26. Markham $\mathrm{CH}$, Diamond SG. Evidence to support early levodopa therapy in Parkinson's disease. Neurology. 1981;31:121-31.

27. Webster DD. Critical analysis of the disability in Parkinson's disease. Mod Treat. 1968;5:257-82.

28. Fahn S, Elton RL, UPDRSDevelopmentCommittee. Unified Parkinson's disease rating scale. In: Fahn S, Marsden CD, Calne D, Goldstein M, editors. Recent Developments in Parkinson's Disease. Florham Park, NJ: MacMillan Healthcare Information; 1987:153-305.

29. Rajput AH, Uitti RJ, Offord KP. Timely levodopa (LD) administration prolongs survival in Parkinson's disease. Parkinsonism Relat Disord. 1997;3:159-65.

30. Goetz CG, Poewe W, Rascol O, et al. Movement Disorder Society Task Force report on the Hoehn and Yahr staging scale: status and recommendations. Mov Disord. 2004;19:1020-8.

31. Rajput AH, Voll A, Rajput ML, Robinson CA, Rajput A. Course in Parkinson disease subtypes: A 39-year clinicopathologic study. Neurology. 2009;73:206-12.

32. Jellinger K. The pathology of Parkinsonism. In: Marsden CD, Fahn S editors. Movement Disorders 2. London: Butterworth and Co,; 1987:124-65.

33. Gelb DJ, Oliver E, Gilman S. Diagnostic criteria for Parkinson disease. Arch Neurol. 1999;56:33-9.

34. Duvoisin R, Goble LI. Toward a definition of Parkinson's disease. Neurology. 1989;39:746.

35. Gustavsson EK, Trinh J, Guella I, et al. DNAJC13 genetic variants in parkinsonism. Mov Disord. 2015;30:273-8.

36. Dickson DW, Braak H, Duda JE, et al. Neuropathological assessment of Parkinson's disease: Refining the diagnostic criteria. Lancet Neurol. 2009;8:1150-7.
37. Foltynie T, Brayne C, Barker RA. The heterogeneity of idiopathic Parkinson's disease. J Neurol. 2002;249:138-45.

38. Schrag A, Ben-Shlomo Y, Brown R, Marsden CD, Quinn N. Youngonset Parkinson's disease revisited-clinical features, natural history, and mortality. Mov Disord. 1998;13:885-94.

39. Lewis SJG, Foltynie T, Blackwell AD, Robbins TW, Owen AM, Barker RA. Heterogeneity of Parkinson's disease in the early clinical stages using a data driven approach. J Neurol Neurosurg Psychiatry. 2005;76:343-8.

40. Marder K, Levy G, Louis ED, et al. Familial aggregation of early- and late-onset Parkinson's disease. Ann Neurol. 2003;54: 507-13.

41. Ferguson LW, Rajput ML, Muhajarine N, Shah SM, Rajput A. Clinical features at first visit and rapid disease progression in Parkinson's disease. Parkinsonism Relat Disord. 2008;14:431-5.

42. Liu P, Feng T, Wang YJ, Zhang X, Chen B. Clinical heterogeneity in patients with early-stage Parkinson's disease: a cluster analysis. J Zhejiang Univ Sci B. 2011;12:694-703.

43. Schrag A, Quinn NP, Ben-Shlomo Y. Heterogeneity of Parkinson's disease. J Neurol Neurosurg Psychiatry. 2006;77:275-6.

44. Dauer W, Przedborski S. Parkinson's disease: mechanisms and models. Neuron. 2003;39:889-909.

45. Hindle JV. Ageing, neurodegeneration and Parkinson's disease. Age Ageing. 2010;39:156-61.

46. Rajput A, Uitti RJ, Lang AE, Rajput AH. Amantadine (Amd) ameliorates levodopa (LD) induced dyskinesias (DK). Neurology. 1997;48:A328.

47. Uitti RJ, Rajput AH, Ahlskog JE, et al. Amantadine treatment is an independent predictor of improved survival in Parkinson's disease. Neurology. 1996;46:1551-6.

48. Spica V, Pekmezovic T, Svetel M, Kostic VS. Prevalence of nonmotor symptoms in young-onset versus late-onset Parkinson's disease. J Neurol. 2013;260:131-7.

49. Reijnders JS, Ehrt U, Lousberg R, Aarsland D, Leentjens AF. The association between motor subtypes and psychopathology in Parkinson's disease. Parkinsonism Relat Disord. 2009;15: 379-82.

50. Jankovic J. Motor fluctuations and dyskinesias in Parkinson's disease: clinical manifestations. Mov Disord. 2005;20 (Suppl 11):S11-6.

51. Ku S, Glass GA. Age of Parkinson's disease onset as a predictor for the development of dyskinesia. Mov Disord. 2010;25: 1177-82.

52. Kumar N, Van Gerpen JA, Bower JH, Ahlskog JE. Levodopadyskinesia incidence by age of Parkinson's disease onset. Mov Disord. 2005;20(3):342-4.

53. Sato K, Hatano T, Yamashiro K, et al. Prognosis of Parkinson's disease: Time to Stage III, IV, V and to motor fluctuations. Mov Disord. 2006;21:1384-95.

54. Alves G, Wentzel-Larsen T, Aarsland D, Larsen JP. Progression of motor impairment and disability in Parkinson disease: a population-based study. Neurology. 2005;65:1436-41.

55. Hely MA, Morris JG, Traficante R, Reid WG, O'Sullivan DJ, Williamson PM. The Sydney multicentre study of Parkinson's disease: progression and mortality at 10 years. J Neurol Neurosurg Psychiatry. 1999;67:300-7.

56. Kostic VS, Marinkovic J, Svetel M, Stefanova E, Przedborski S. The effect of stage of Parkinson's disease at the onset of levodopa therapy on development of motor complications. Eur J Neurol. 2002;9:9-14.

57. Muller J, Wenning GK, Jellinger K, McKee A, Poewe W, Litvan I. Progression of Hoehn and Yahr stages in Parkinsonian disorders: a clinicopathologic study. Neurology. 2000;55:888-91. 